Western University

Scholarship@Western

Chemistry Publications

Chemistry Department

Fall 12-14-2016

\title{
End-Capping Strategies for Triggering End-to-End Depolymerization of Polyglyoxylates
}

Bo Fan

Western University,bfan25@uwo.ca

John Trant

Western University

Elizabeth Gillies

Western University, egillie@uwo.ca

Follow this and additional works at: https://ir.lib.uwo.ca/chempub

Part of the Polymer Chemistry Commons

Citation of this paper:

Fan, Bo; Trant, John; and Gillies, Elizabeth, "End-Capping Strategies for Triggering End-to-End Depolymerization of Polyglyoxylates" (2016). Chemistry Publications. 94.

https://ir.lib.uwo.ca/chempub/94 


\section{End-capping strategies for triggering end-to-end depolymerization of polyglyoxylates}

Bo Fan, ${ }^{\dagger}$ John F. Trant, ${ }^{\ddagger}$ and Elizabeth R. Gillies ${ }^{\dagger}+* *$

†Department of Chemical and Biochemical Engineering, The University of Western Ontario, 1151 Richmond St., London, Ontario, Canada, N6A 5B9

Department of Chemistry, The University of Western Ontario, 1151 Richmond St., London, Ontario, Canada, N6A 5B7

*Author to whom correspondence should be addressed: E-mail: egillie@uwo.ca 


\section{for Table of Contents use only}

End-capping strategies for triggering end-to-end depolymerization of polyglyoxylates

Bo Fan, John F. Trant, and Elizabeth R. Gillies*

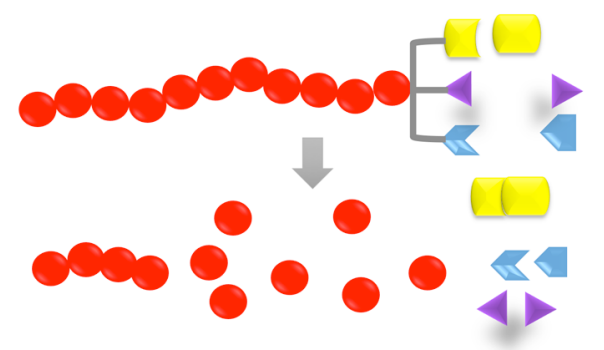




\begin{abstract}
Polymers that undergo end-to-end depolymerization in response to the cleavage of a stimuli-responsive end-cap are promising for diverse applications from drug delivery to responsive coatings and plastics. It is critical that the end-cap is designed to respond to an appropriate stimulus for the application. In the current work, end-caps for triggering the depolymerization of poly(ethyl glyoxylate) (PEtG) were explored. First a phenylboronate, a disulfide, and an azobenzene were utilized to impart redox-responsive properties to PEtG. Then, methoxy-substituted trityl groups were used to provide sensitivity to mild acid. A multi-responsive platform was also introduced, allowing PEtG to respond to multiple stimuli, either simultaneously or independently. Incorporation of a cross-linkable trialkene end-cap enabled the preparation of networks that could subsequently be depolymerized. Finally, high molar mass PEtG could be depolymerized by mechanical stimulation independent of the end-cap. It is anticipated that the versatility in end-capping strategies and potential depolymerization stimuli will not only expand PEtG's utility for different applications, but will also be useful for other classes of end-to-end depolymerizable polymers.
\end{abstract}

\title{
Introduction
}

Degradable polymers are of significant interest, both as environmentally-friendly replacements for traditional non-degradable polymers and for wide range of biomedical applications from tissue engineering to drug delivery. ${ }^{1-3}$ Biodegradable polyesters such as poly(lactic acid), 
poly(glycolic acid), polycaprolactone, and polyhydroxybutyrate have been extensively investigated and show promise in many applications. ${ }^{4,5}$ However, their tendency to undergo slow degradation in a variety of environments is a potential limitation as they may decompose prematurely while still in use or may decompose more slowly than desired in other cases. ${ }^{6,7}$ While their degradation rates can be tuned to some extent based on their chemical structure, molar mass and through formulation adjustments, ${ }^{8,9}$ the ability to "turn on" their degradation at the desired time and place is still quite limited.

Over the past decade, a new class of degradable polymers that depolymerize end-to-end upon the cleavage of a stimuli-responsive end-cap from the polymer terminus was introduced. ${ }^{10-12}$ These have often been referred to as "self-immolative" polymers as they were initially inspired by the analogous dendritic structures composed of "self-immolative spacers" that were developed for pro-drug chemistry. ${ }^{13}$ Following cleavage of the stabilizing end-cap, the mechanism of depolymerization can involve sequential elimination or cyclization reactions that result in conversion of the polymer to small molecules that differ from the monomers from which they were prepared. Alternatively, it can involve sequential loss of monomer units from the polymer terminus due to the low ceiling temperature of the polymer. Thus far, a number of depolymerizable backbones have been introduced including polycarbamates, ${ }^{14-17}$ polycarbonates ${ }^{18}$ polythiocarbamates,${ }^{19}$ polythiocarbonates, ${ }^{18}$ poly(benzyl ether) $\mathrm{s}^{20}$ and polyacetals. $^{21-27}$

For end-to-end depolymerizable polymers, a single end-cap cleavage reaction is theoretically sufficient to trigger degradation of the entire polymer backbone. This potentially provides higher 
sensitivity to stimuli than traditional stimuli-responsive polymers that require many stimuli-mediated events to degrade the backbone. This has made these polymers attractive for a variety of applications, and proof-of-concept studies have been performed to demonstrate their potential utility as drug delivery systems, ${ }^{16,28-30}$ molecular sensors,,${ }^{14,16,31,32}$ micropumps,${ }^{33}$ responsive films or plastics, ${ }^{21,34,35}$ stimuli-responsive microcapsules, ${ }^{36,37}$ and for simple polymer reprogramming or recycling. ${ }^{27,35,38} \mathrm{~A}$ key aspect determining the potential of the polymer for a given application is the ability to match the polymer end-cap with suitable triggering conditions that are relevant to that application. For example, end-caps responsive to light, ${ }^{28,30,39}$ enzymes $^{29}$ and reducing conditions ${ }^{19,30}$ have been used to trigger release from proof of concept drug delivery systems. End-caps sensitive to fluoride ions have been used in responsive adhesives, ${ }^{34}$ plastics, ${ }^{21,40}$ and microcapsules. ${ }^{37}$ Furthermore, end-caps responsive to $\mathrm{H}_{2} \mathrm{O}_{2}$ have been used in sensors. ${ }^{31,32}$ Polyglyoxylates were recently reported by our group as a class of end-to-end depolymerizable polymers with attractive features such as ease of synthesis from readily available monomers, degradation to non-toxic products, ${ }^{41}$ and the ability to undergo depolymerization in the solid state to volatile products (Figure 1). ${ }^{35}$ In comparison with earlier polyglyoxylates that were not responsive to stimuli, ${ }^{42,43}$ the development of stimuli-responsive polyglyoxylates was made possible through end-capping with chloroformates. This chemistry was feasible because of the high reactivity of chloroformates, which allows the reaction to be performed at low temperature $\left(-20^{\circ} \mathrm{C}\right)$, below the ceiling temperature of the polyglyoxylate in solution. However, thus far only UV light-responsive polyglyoxylates were reported. ${ }^{24}$ In the current study, using poly(ethyl glyoxylate) (PEtG) it is demonstrated that this end-capping 
strategy can be extended to other end-caps responsive to oxidizing and reducing conditions. In addition, the development of new end-caps responsive to mildly acidic conditions is described. It is further shown that an end-cap responsive to multiple stimuli as well as one that enables subsequent cross-linking of the polyglyoxylate to afford a depolymerizable gel can be designed. It is also demonstrated that mechanical force can be used to selectively depolymerize high molar mass PEtG.

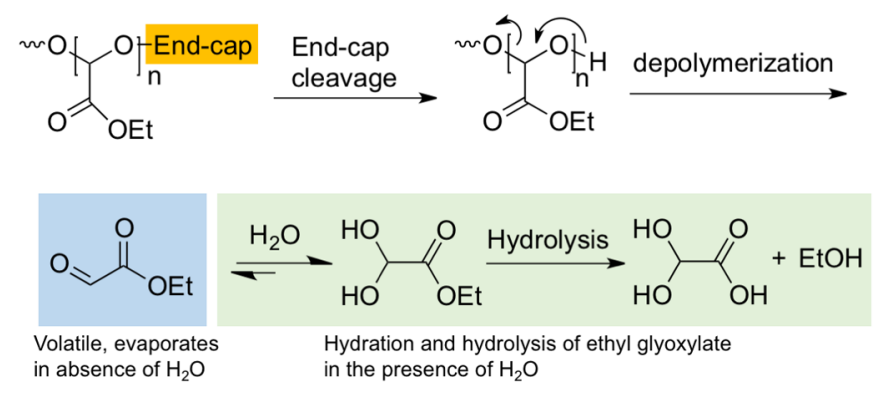

Figure 1. Schematic illustrating the end-cap cleavage and depolymerization process for PEtG.

\section{Experimental section}

General procedures and materials. Compounds $\mathbf{2}^{44}, 3^{45}, \mathbf{9}^{46}, \mathbf{1 2}^{47}, \mathbf{1 3}^{48}$ and PEtG-control ${ }^{35}$ were prepared as previously reported. Additional experimental procedures are included in the supporting information. $\mathrm{NEt}_{3}$, pyridine, and $\mathrm{CH}_{2} \mathrm{Cl}_{2}$ were distilled from calcium hydride before use. Anhydrous tetrahydrofuran (THF) was obtained from a solvent purification system using aluminum oxide columns from Innovative Technology (Newburyport, MA). All the other chemicals were purchased from chemical suppliers and used without further purification. NMR spectra were obtained on $400 \mathrm{MHz}$ or $600 \mathrm{MHz}$ Varian Inova spectrometers (Agilent Tech., Santa Clara, CA). NMR chemical shifts $(\delta)$ are reported in ppm and are calibrated against the residual 
solvent signals of $\mathrm{CDCl}_{3}(\delta 7.27 ; 77.4), \mathrm{CD}_{3} \mathrm{CN}(\delta 1.94 ; 116.4), d_{6}$-DMSO $(\delta 2.50 ; 40.8)$ or $\mathrm{D}_{2} \mathrm{O}$

$(\delta$ 4.75). Fourier transform infrared (FT-IR) spectra were obtained using a Bruker Tensor 27

instrument (Billerica, MA) using thin films of the molecules drop cast from $\mathrm{CH}_{2} \mathrm{Cl}_{2}$ on $\mathrm{KBr}$ plates.

High-resolution mass spectrometry (HRMS) was performed using a Finnigan MAT 8400 electron impact (EI) mass spectrometer or Bruker microOTOF 11 electrospray mass spectrometer (ESI).

Size exclusion chromatography (SEC) was performed using a Viscotek GPC Max VE2001 solvent module (Agilent Tech.), a Viscotek VE3580 RI detector operating at $30{ }^{\circ} \mathrm{C}$, two Agilent Polypore $(300 \times 7.5 \mathrm{~mm})$ columns connected and a Polypore guard column $(50 \times 7.5 \mathrm{~mm})$. THF (glass distilled grade) was used as the eluent. A calibration curve was obtained from poly(methyl methacrylate) (PMMA) standards with molar masses from $1540-1126000 \mathrm{~g} / \mathrm{mol}$. Differential scanning calorimetry (DSC) was performed using a Q2000 from TA Instruments (New Castle, DE) and thermogravimetric analysis (TGA) was performed on Q50 from TA Instruments. For TGA the heating rate was $10^{\circ} \mathrm{C} / \mathrm{min}$ between $35-500^{\circ} \mathrm{C}$ under nitrogen. For DSC, the heating/cooling rate was $10^{\circ} \mathrm{C} / \mathrm{min}$ from -75 to $+120^{\circ} \mathrm{C}$. Glass transition temperatures $\left(\mathrm{T}_{\mathrm{g}}\right)$ were obtained from the second heating cycle.

\section{Synthesis of chloroformate 5 (representative procedure for chloroformate synthesis).}

Compound $2^{44}$ (500 mg, 2.7 mmol, 1.0 equiv.) was dissolved in THF (10 mL). The resulting solution was then added dropwise into a phosgene solution $(15 \mathrm{wt} \%$ in toluene, $5.8 \mathrm{~mL}, 8.1 \mathrm{mmol}$, 3.0 equiv.) under an argon atmosphere at room temperature and the resulting solution was stirred for $24 \mathrm{~h}$. The residual phosgene and solvent were then removed by distillation in vacuo to yield chloroformate 5 (750 mg, 98\%) as a pale brown solid. Phosgene collected in the liquid 
nitrogen-cooled trap was then quenched with methanol $(20 \mathrm{~mL})$ and saturated sodium hydroxide solution $(20 \mathrm{~mL})$ (Caution! phosgene is toxic). ${ }^{1} \mathrm{H}$ NMR $\left(400 \mathrm{MHz}, \mathrm{CDCl}_{3}\right): \delta 8.76-8.84(\mathrm{~m}$, $1 \mathrm{H}), 8.20-8.30(\mathrm{~m}, 1 \mathrm{H}), 8.17(\mathrm{~d}, J=8.2 \mathrm{~Hz}, 1 \mathrm{H}) 7.65-7.73(\mathrm{~m}, 1 \mathrm{H}), 4.61(\mathrm{t}, J=5.9 \mathrm{~Hz}, 2 \mathrm{H}), 3.34$ $(\mathrm{t}, J=5.9 \mathrm{~Hz}, 2 \mathrm{H}) .{ }^{13} \mathrm{C}$ NMR $\left(150 \mathrm{MHz}, \mathrm{CDCl}_{3}\right): \delta 156.9,150.5,145.2,142.9,125.0,123.9,68.8$, 37.8. HRMS (EI) calc'd. for [M] ${ }^{+} \mathrm{C}_{8} \mathrm{H}_{8} \mathrm{ClNO}_{2} \mathrm{~S}_{2}$ : 248.9685; found: 248.9689.

\section{Synthesis of PEtG-boronate (representative procedure for the synthesis of end-capped PEtG).}

Ethyl glyoxylate in toluene $(20 \mathrm{~mL})$ was distilled under vacuum $\left(55^{\circ} \mathrm{C}, 125 \mathrm{mbar}\right)$ over $\mathrm{P}_{2} \mathrm{O}_{5}$ to remove toluene and trace water in the first, discarded fraction. The residue was then distilled twice successively over $\mathrm{P}_{2} \mathrm{O}_{5}$ at atmospheric pressure under argon at $130{ }^{\circ} \mathrm{C}$ to obtain the highly pure monomer. Purified ethyl glyoxylate (5.0 mL, 50 mmol, 1.0 equiv.) was dissolved in $\mathrm{CH}_{2} \mathrm{Cl}_{2}(5.0$ $\mathrm{mL}$ ), cooled to $-20{ }^{\circ} \mathrm{C}$, and $\mathrm{Et}_{3} \mathrm{~N}$ ( $3.5 \mu \mathrm{L}, 25 \mu \mathrm{mol}, 0.0005$ equiv.) was added. The solution was stirred for $1 \mathrm{~h}$ at $-20^{\circ} \mathrm{C}$. Chloroformate $4(0.22 \mathrm{~g}, 730 \mu \mathrm{mol}, 0.014$ equiv. $)$ and $\mathrm{Et}_{3} \mathrm{~N}(100 \mu \mathrm{L}, 730$ $\mu$ mol, 0.014 equiv.) were added. The solution was allowed to slowly warm to room temperature over a few hours, and then stirred overnight. The resulting polymer was purified by precipitation into methanol. After decanting the excess methanol, the residue was dried in vacuo to provide 3.3 g of a white, sticky polymer in $63 \%$ yield. ${ }^{1} \mathrm{H}$ NMR $\left(400 \mathrm{MHz}, \mathrm{CDCl}_{3}\right): \delta 7.80(\mathrm{~d}, J=8.6 \mathrm{~Hz}, 2 \mathrm{H})$, $7.53(\mathrm{~d}, J=8.6 \mathrm{~Hz}, 2 \mathrm{H}), 5.46-5.78(\mathrm{~m}, 675 \mathrm{H}), 4.10-4.33(\mathrm{~m}, 1367 \mathrm{H}), 1.34(\mathrm{~s}, 12 \mathrm{H}), 1.21-1.44(\mathrm{~m}$, 2000H). IR (KBr, thin film): 2986, 2943, 2908, 1759, 1469, 1446, 1377, 1302, 858, 735, $702 \mathrm{~cm}^{-1}$. SEC: $\mathrm{M}_{\mathrm{n}}=131 \mathrm{~kg} / \mathrm{mol}, \mathrm{M}_{\mathrm{w}}=304 \mathrm{~kg} / \mathrm{mol}, \nexists=2.3 . \mathrm{T}_{\mathrm{g}}=-1^{\circ} \mathrm{C}$.

Procedure for the study of PEtG-boronate depolymerization by ${ }^{1}$ H NMR spectroscopy (representative depolymerization procedure). PEtG-boronate (15 mg) was dissolved in a 9:1 
$\mathrm{CD}_{3} \mathrm{CN}: \mathrm{D}_{2} \mathrm{O}(1.2 \mathrm{~mL})$. The solution was then divided between two NMR tubes and $4 \mu \mathrm{L}$ of $\mathrm{H}_{2} \mathrm{O}_{2}$ (50 $\mathrm{wt} \%$ in water solution) was added to one tube to provide an $\mathrm{H}_{2} \mathrm{O}_{2}$ concentration of $\sim 100 \mathrm{mM}$. The tubes were sealed, maintained at ambient temperature $\left(20{ }^{\circ} \mathrm{C}\right)$, and ${ }^{1} \mathrm{H}$ NMR spectra were obtained at time points over $48 \mathrm{~h}$ for both the triggered polymer and the control. At the same time, a non-stimuli-responsive PEtG-control with a benzyl carbonate end-cap was also exposed to the same concentration of $\mathrm{H}_{2} \mathrm{O}_{2}$ following the same procedure as above and its depolymerization was also monitored by ${ }^{1} \mathrm{H}$ NMR spectroscopy. The extent of depolymerization was calculated as: $\%$ depolymerization $=100-\mathrm{x}$, where $\mathrm{x}$ is the integration of the peak at $5.5 \mathrm{ppm}$, when the integration of the peak at $4.2 \mathrm{ppm}$ was set to 200 (which remained constant as it corresponds to the $\mathrm{CH}_{3} \mathrm{CH}_{2}-\mathrm{O}$ - in both the polymer and the depolymerization products).

\section{Results and Discussion}

\section{Development of redox-responsive PEtG}

Polymer systems that respond to oxidizing or reducing conditions have been actively sought for the past several years due to the practical interest in these stimuli. ${ }^{49-51}$ For example, increased concentrations of the reducing agent glutathione are associated with the intracellular environment as well as with hypoxic tumor tissue, potentially allowing drug molecules to be selectively released from reduction-sensitive polymers in these environments. ${ }^{52,53}$ Reactive oxygen species are also associated with a wide range of pathologies including inflammation and tissue injury. ${ }^{54}$ While end-to-end depolymerization has previously been initiated by these stimuli, ${ }^{19,30-32}$ oxidation- 
and reduction-sensitive PEtGs were chosen as initial targets to explore the versatility of the chloroformate end-capping strategy for PEtG and the response of PEtG to these stimuli.

A phenylboronic acid pinacol ester was selected as the $\mathrm{H}_{2} \mathrm{O}_{2}$-sensitive end-cap. ${ }^{55}$ As shown in Figure 2a, in the presence of $\mathrm{H}_{2} \mathrm{O}_{2}$ this end-cap undergoes cleavage to the corresponding phenol, which can then undergo a 1,6-elimination followed by loss of $\mathrm{CO}_{2}$, releasing the PEtG hemiacetal terminus and triggering depolymerization. The thiol-responsive pyridyl disulfide was selected based on its well-established sensitivity to reduction by thiols as well as its successful use as an end-cap for depolymerizable polycarbonates and poly(carbamate-thiocarbamate)s. ${ }^{18,19}$ Reductive cleavage of the disulfide reveals a thiol that can subsequently cyclize to form either a cyclic thiocarbonate (Figure $2 \mathrm{~b}$ ) or a thiirane ring followed by loss of $\mathrm{CO}_{2}$, releasing the PEtG terminus. ${ }^{56}$ Finally, an azobenzene moiety was also explored as a reduction-sensitive end-cap. Recent work from our group has shown that the reduction of azobenzene end-caps with hydrazine can trigger end-to-end depolymerization of polycarbamates and studies on small molecule model compounds suggested that the reduction should also be possible with thiols. ${ }^{57}$ As shown in Figure 2c, reduction leads an electron-rich hydrazobenzene that can undergo a 1,6-elimination, followed by loss of $\mathrm{CO}_{2}$ to release the polymer terminus. 
a)

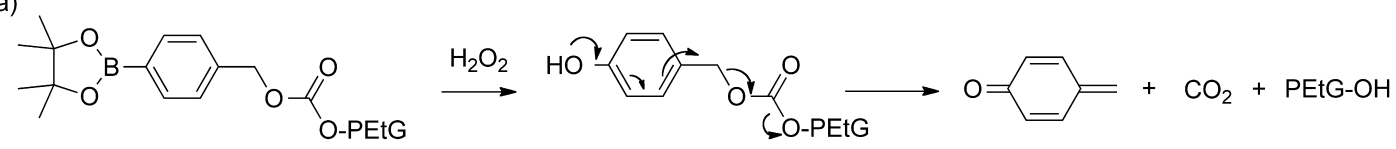

b)

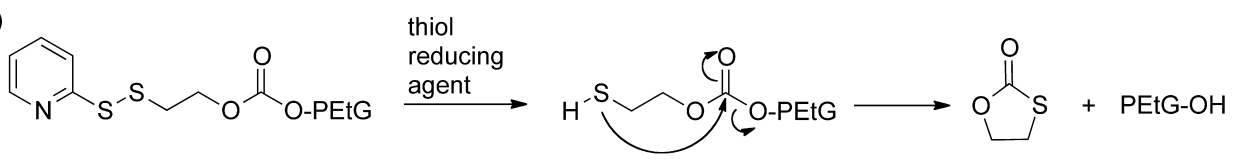

c)

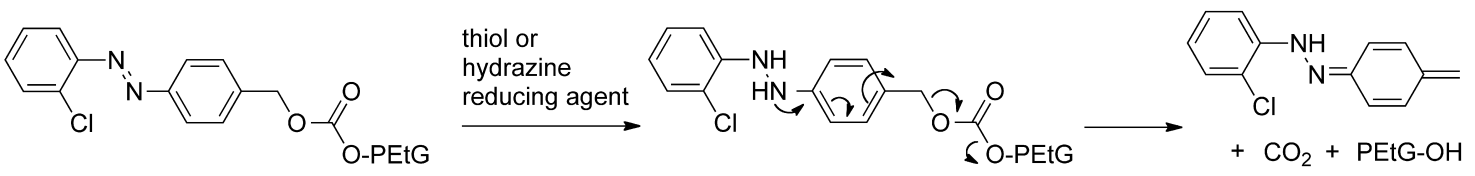

Figure 2. Proposed triggering mechanisms for redox-responsive PEtG end-caps.

As shown in Scheme 1, alcohol derivatives of the boronate (1), disulfide (2) ${ }^{44}$ and azobenzene $(3)^{57}$ were reacted with phosgene in THF/toluene to afford the corresponding chloroformates 4 - 6 .

The disulfide end-cap was isolated as its $\mathrm{HCl}$ salt. Polymerization of freshly distilled ethyl glyoxylate was initiated by the addition of $\mathrm{NEt}_{3}$ and was conducted at $-20{ }^{\circ} \mathrm{C}$ as previously reported (Scheme 2). ${ }^{24}$ The resulting PEtG was end-capped in situ by the addition of the chloroformate and additional $\mathrm{NEt}_{3}$ at $-20{ }^{\circ} \mathrm{C}$, and the reaction was allowed to slowly reach ambient temperature and stirred overnight, affording PEtG-boronate, PEtG-disulfide, and PEtG-azobenzene from chloroformates 4, 5, and 6 respectively. In addition to the chloroformates 4 - 6, benzyl chloroformate was used to provide a non-responsive control carbonate end-capped PEtG (PEtG-control) as previously reported. ${ }^{35}$ 

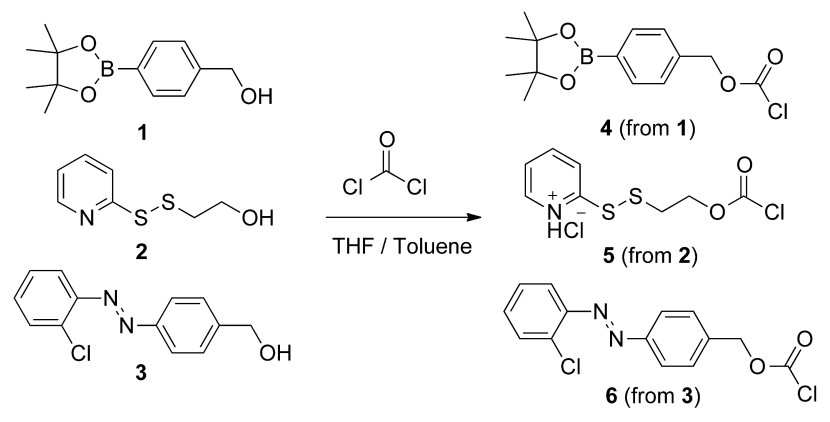

Scheme 1. Synthesis of chloroformate end-caps 4 - 6.

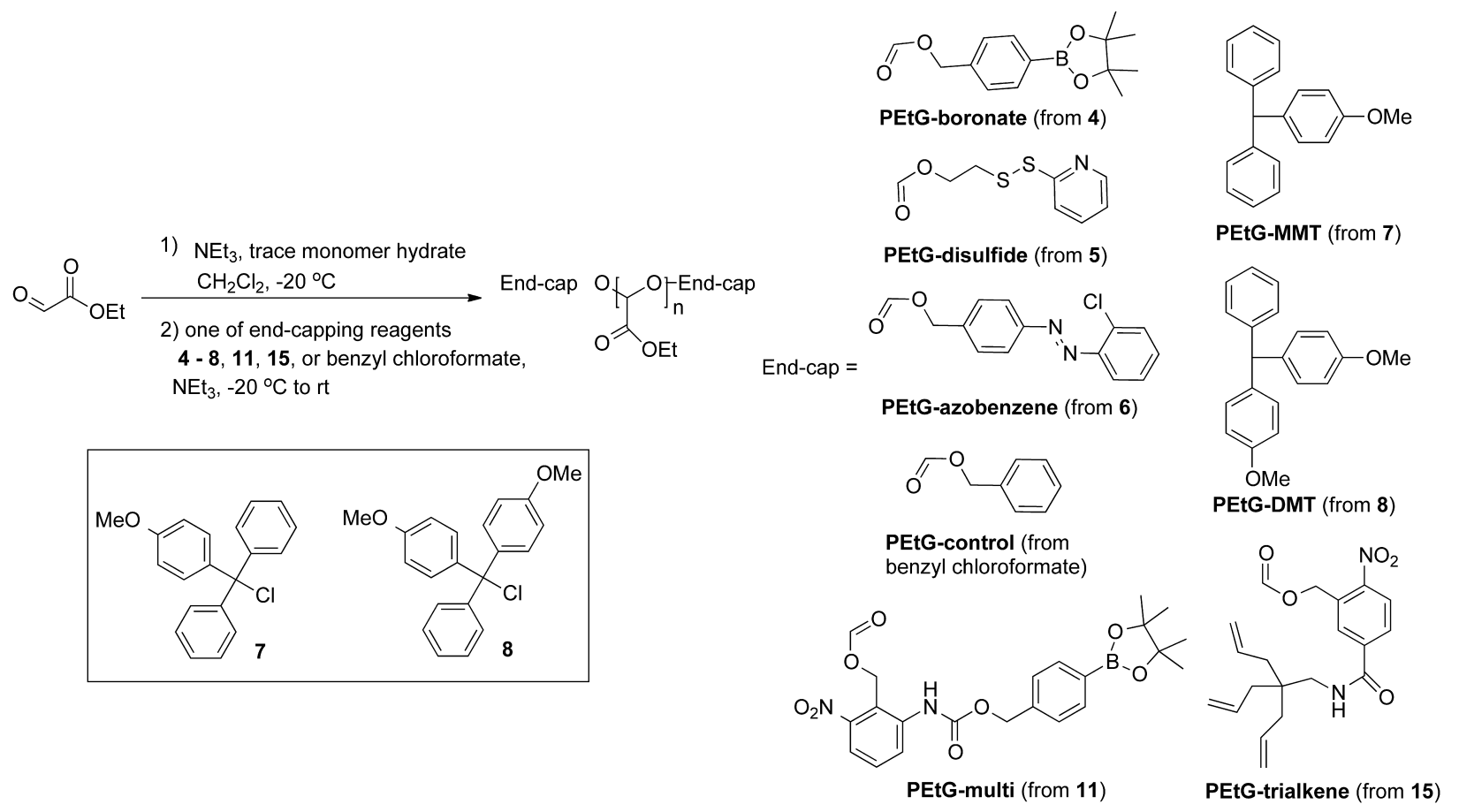

Scheme 2. Synthesis and end-capping of PEtG.

The end-capped polymers were characterized by SEC, NMR spectroscopy, DSC and TGA. As shown in Table 1, based on SEC the number average molar masses $\left(M_{n}\right)$ of these polymers ranged from $24-250 \mathrm{~kg} / \mathrm{mol}$ and their dispersities $(\bigoplus)$ ranged from $1.3-2.3$. The variation in $M_{n}$ between the different polymers likely results from the fact that these polymers were prepared from different batches of distilled monomer, as we have observed a strong dependency of $M_{n}$ on 
the purity of monomer. This dependency arises from the initiation of the polymerization from trace ethyl glyoxylate hydrate (EtGH) that is present in the distilled monomer. Different batches of distilled monomer contain different amounts of this initiator. Although in principle, it should be possible to achieve a controlled polymerization of PEtG by adding a defined amount of initiator, this has not yet been achieved. In each case, NMR spectroscopy showed very small peaks consistent with the presence of the appropriate end-caps on the polymers. However, given the high degrees of polymerization (DP), these peaks were challenging to detect and accurately integrate, so DP was not determined by NMR spectroscopy. It was previously demonstrated that TGA provides an excellent indicator of successful end-capping as uncapped polymer is thermally unstable and depolymerizes below $100{ }^{\circ} \mathrm{C}$ in the solid state. Even small fractions of uncapped polymer can be detected by TGA. ${ }^{24}$ As shown in Table 1 and Figure S46, the polymers had onset degradation temperatures $\left(\mathrm{T}_{\mathrm{o}}\right)$ from $183-255^{\circ} \mathrm{C}$, confirming that they were well end-capped. In addition, through the preparation and analysis of two different batches of PEtG-disulfide (a and b) with a $\sim 10$-fold difference in $\mathrm{M}_{\mathrm{n}}$, it was confirmed that the PEtG molar mass did not have a significant effect on its thermal stability. Based on DSC, the $T_{g}$ values were very similar for the different end-capped PEtGs, ranging from -7 to $-1{ }^{\circ} \mathrm{C}$. 
Table 1. Molar mass and thermal properties of end-capped PEtGs and measured by SEC, TGA, and DSC.

\begin{tabular}{|l|l|l|l|l|}
\hline Polymer & $\mathrm{M}_{\mathrm{n}}$ & Dispersity & $\mathrm{T}_{\mathrm{o}}$ & $\mathrm{T}_{\mathrm{g}}$ \\
& $(\mathrm{SEC})$ & $(Đ)$ & $\left({ }^{\circ} \mathrm{C}\right)$ & $\left({ }^{\circ} \mathrm{C}\right)$ \\
\hline PEtG-boronate & 131 & 2.3 & 226 & -1 \\
\hline PEtG-disulfide-a & 250 & 1.7 & 183 & -7 \\
\hline PEtG-disulfide-b & 26 & 1.4 & 191 & -7 \\
\hline PEtG-azobenzene & 30 & 1.4 & 255 & -1 \\
\hline PEtG-control & 35 & 1.4 & 247 & -3 \\
\hline PEtG-DMT & 21 & 1.3 & 131 & -10 \\
\hline PEtG-MMT & 29 & 1.5 & 168 & -1 \\
\hline PEtG-multi & 41 & 1.6 & 164 & -4 \\
\hline PEtG-trialkene & 11 & 1.7 & 225 & -7 \\
\hline PEtG-crosslinked & $\mathrm{N} / \mathrm{A}$ & $\mathrm{N} / \mathrm{A}$ & 191 & 5 \\
\hline
\end{tabular}

The depolymerization of the redox-responsive polymers and PEtG-control was then studied in the presence and absence of the corresponding stimuli. PEtG is not soluble in water, but it was possible to dissolve the polymers in $9: 1 \mathrm{CD}_{3} \mathrm{CN}: \mathrm{D}_{2} \mathrm{O}$ in order to study the depolymerization by ${ }^{1} \mathrm{H}$ NMR spectroscopy. First, the response of PEtG-boronate to $\mathrm{H}_{2} \mathrm{O}_{2}$ was studied. Prior to the 
addition of $\mathrm{H}_{2} \mathrm{O}_{2}$, the spectrum had three broad peaks corresponding to the protons on the PEtG backbone and pendant ester groups (Figure 3a). Following the addition of $\mathrm{H}_{2} \mathrm{O}_{2}$, the broad peak at $5.5 \mathrm{ppm}$ corresponding to backbone methine protons rapidly decreased in intensity while two new sharp peaks at $5.3 \mathrm{ppm}$ and $5.1 \mathrm{ppm}$ emerged. The sharp peak at $5.1 \mathrm{ppm}$ corresponds to the degradation product EtGH as described previously. ${ }^{24}$ The new peak at 5.3 ppm can be attributed to a peroxy hydrate of ethyl glyoxylate arising from the increased nucleophilicity of $\mathrm{H}_{2} \mathrm{O}_{2}$ compared to water due to the $\alpha$-effect. ${ }^{58}$ The same product could be formed by the direct addition of ethyl glyoxyate into the above degradation conditions, and was fully characterized by ${ }^{1} \mathrm{H}$ and ${ }^{13} \mathrm{C}$ NMR spectroscopy and high resolution mass spectrometry (Figures S23-S25).

a)

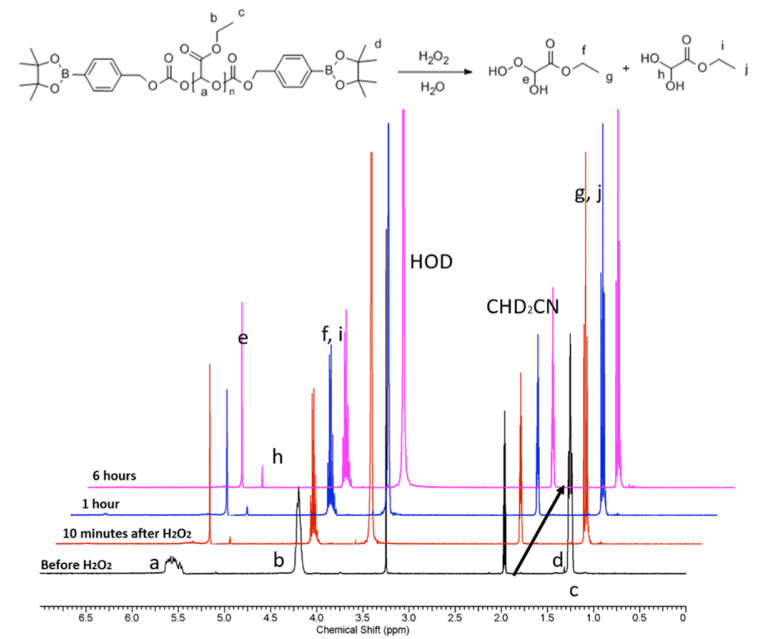

b)

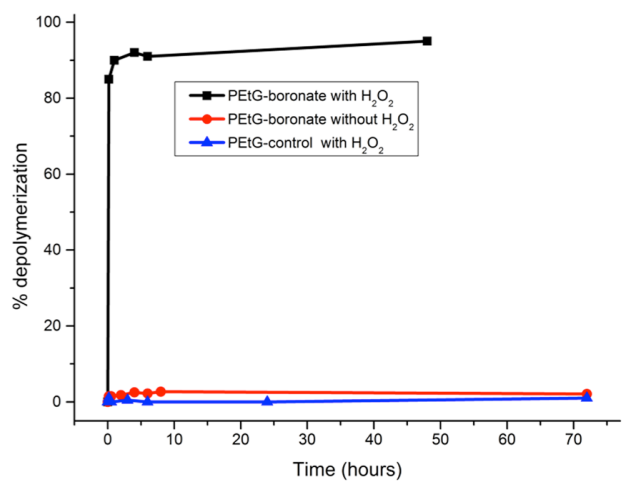

c)

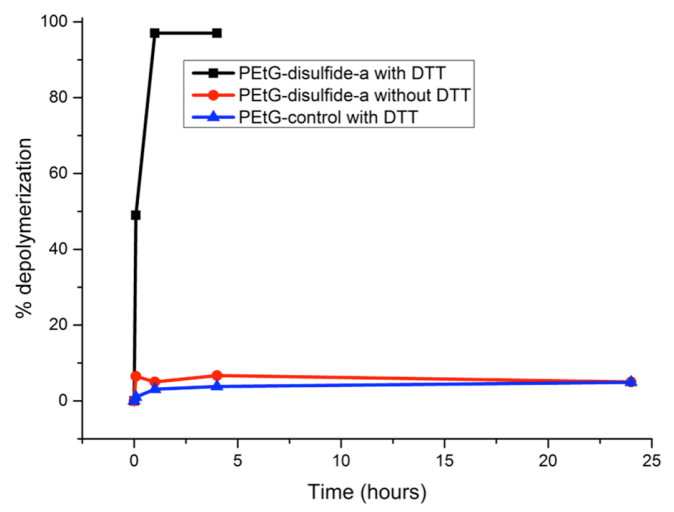

d)

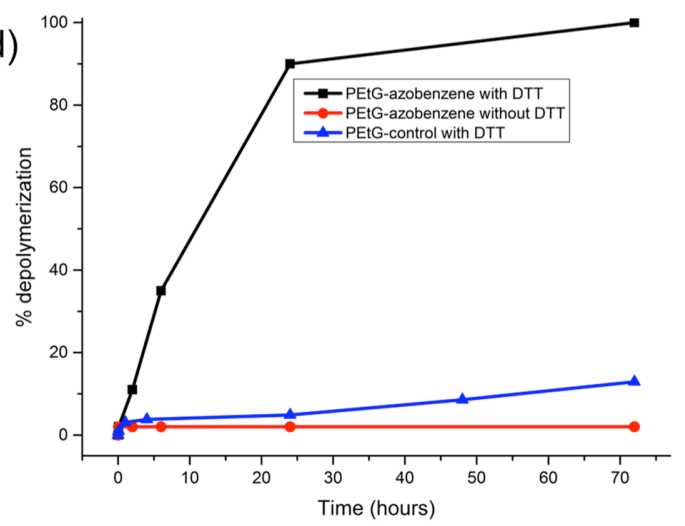


Figure 3. a) ${ }^{1} \mathrm{H}$ NMR spectra of PEtG-boronate in 9:1 $\mathrm{CD}_{3} \mathrm{CN}: \mathrm{D}_{2} \mathrm{O}$ before addition of $\mathrm{H}_{2} \mathrm{O}_{2}$ and at various time points after $\mathrm{H}_{2} \mathrm{O}_{2}$ addition (spectra are offset to allow the progression over time to be clearly observed); b-d) Percent depolymerization versus time in the presence and absence of stimuli for b) PEtG-boronate, c) PEtG-disulfide-a, and d) PEtG-azobenzene. In each case, PEtG-control was also exposed to the stimulus to confirm specific cleavage of the end-cap.

The percent depolymerization, defined as the percentage of the monomer released as small molecule from the polymer, as a function of time for PEtG-boronate is shown in Figure 3b. It was noted that depolymerization was more rapid than previously observed following the cleavage of the UV light-sensitive 6-nitroveratryl end-cap from our previous work. ${ }^{24}$ For example, $80 \%$ depolymerization had occurred in 10 minutes for PEtG-boronate, while 70\% was observed after $24 \mathrm{~h}$ for the previous system. This difference can likely be attributed to the rapid trapping of the ethyl glyoxylate depolymerization product as the peroxy hydrate. However, the drawback of this trapping reaction is that high concentrations of $\mathrm{H}_{2} \mathrm{O}_{2}(\sim 100 \mathrm{mM})$ were required in order to achieve complete depolymerization. Lower concentrations led to a plateau in the depolymerization because peroxide lost through peroxy hydrate formation was no longer available to cleave the end-cap. The required equivalents of $\mathrm{H}_{2} \mathrm{O}_{2}$ per polymer chain was similar to the DP based on SEC analysis ( 1000). Control experiments showed that in the absence of $\mathrm{H}_{2} \mathrm{O}_{2}$, PEtG-boronate was stable, undergoing less than 3\% depolymerization over 3 days in 9:1 $\mathrm{CD}_{3} \mathrm{CN}: \mathrm{D}_{2} \mathrm{O}$ (Figure $3 \mathrm{~b}$ and $\mathrm{S} 29 \mathrm{a}$ ). Furthermore, PEtG-control did not undergo any detectable depolymerization when treated with 
$100 \mathrm{mM} \mathrm{H}_{2} \mathrm{O}_{2}$ under the same conditions for 7 days (Figure $3 \mathrm{~b}$ and $\mathrm{S} 29 \mathrm{~b}$ ). These results confirm the specificity of $\mathrm{H}_{2} \mathrm{O}_{2}$ for end-cap cleavage rather than backbone cleavage or side reactions.

The same procedure was used to study the depolymerization of PEtG-disulfide-a, except that the reducing agent dithiothreitol (DTT) was used instead of the oxidizing agent $\mathrm{H}_{2} \mathrm{O}_{2}$. As shown in Figure 3c and S30, depolymerization occurred rapidly following DTT addition, with more than 95\% depolymerization observed over $1 \mathrm{~h}$. Like $\mathrm{H}_{2} \mathrm{O}_{2}$, DTT is also a strong nucleophile, and reacted rapidly with ethyl glyoxylate (Figure S26-S28), resulting in the requirement for high $(\sim 110 \mathrm{mM})$ concentrations of DTT in order to achieve complete end-cap cleavage and depolymerization. PEtG-disulfide without DTT and PEtG-control in the presence of $110 \mathrm{mM}$ DTT underwent only 5\% depolymerization over $24 \mathrm{~h}$ (Figure 3c and S31), again showing that DTT could selectively trigger depolymerization through specific end-cap cleavage.

Hydrazine was initially investigated as a trigger for PEtG-azobenzene as it was successfully used as a trigger in the context of polycarbamates and poly(ester amide)s. ${ }^{45,57}$ When $100 \mathrm{mM}$ hydrazine was added to PEtG-azobenzene in 9:1 $\mathrm{CD}_{3} \mathrm{CN}: \mathrm{D}_{2} \mathrm{O}$ solution, rapid depolymerization was observed, but these conditions also resulted in complete depolymerization of PEtG-control, suggesting that hydrazine induced non-specific cleavage of the terminal carbonate or the pendant esters, which could subsequently trigger backbone cleavage and depolymerization. ${ }^{59}$ This could be caused by the basicity or nucleophilicity of hydrazine. Thus, DTT was investigated as a trigger. As shown in Figures 3d and S32, 110 mM DTT could indeed induce depolymerization of PEtG-azobenzene, albeit at a slower rate than for PEtG-disulfide. For example, 35\% depolymerization of PEtG-azobenzene was observed after $6 \mathrm{~h}$, whereas more than $95 \%$ of 
PEtG-disulfide was depolymerized in $1 \mathrm{~h}$. Therefore, end-cap cleavage was the rate-limiting step in this process. In the absence of DTT, $2 \%$ depolymerization of PEtG-azobenzene was observed over 3 days (Figure 3d and S33) and $~ 14 \%$ of PEtG-control depolymerized over this time period in the presence of $110 \mathrm{mM}$ DTT (Figure $3 \mathrm{~d}$ and S31). This suggests that high concentrations of DTT can induce small amounts of non-specific backbone or terminal carbonate cleavage reactions over a period of days. Thus, the azobenzene moiety provides an additional reduction-sensitive end-cap with slower cleavage kinetics that may be useful for some applications, but it is not as selective a trigger as the boronate or carbonate.

\section{Development of acid-responsive PEtG}

Change in $\mathrm{pH}$ is also a stimulus of significant interest. For example, tumor tissue, as well as the endosomes and lysosome of cells are well known to have mildly acid $\mathrm{pH}$ (e.g., $\mathrm{pH} 5$ - 7) relative to the normal neutral physiological $\mathrm{pH}$ of 7.4 , thereby providing a potential mechanism for selectively releasing therapies in these locations. ${ }^{51,60}$ To the best of our knowledge, the use of mildly acidic conditions to trigger end-to-end depolymerization has not yet been reported.

Alcohol protecting groups provide an ideal starting point for the development of acid-sensitive end-caps and our studies began by investigating linkages such as acetals that have been widely exploited in the context of stimuli-responsive polymers. ${ }^{61-63}$ However, the direct end-capping of PEtG with acetal precursors such as vinyl ethers was unsuccessful and the insertion of spacers that would enable chloroformate preparation resulted in poor initiation of the depolymerization due to the requirement for a subsequent slow cyclization of a hydroxyl nucleophile to release the 
PEtG hemiacetal terminus. Fortunately, it was found that triphenylmethyl (trityl) chlorides could be used to directly end-cap PEtG. Trityl groups have been investigated in the context of prodrugs and drug conjugates and can be cleaved in buffers at $\mathrm{pH} 5-7 .{ }^{64}$ As shown in Scheme 2, the use of monomethoxytrityl chloride (7) and dimethoxyltrityl chloride (8) as end-capping reagents led to PEtG-MMT and PEtG-DMT respectively. As shown in Table 1, PEtG-MMT and PEtG-DMT had $\mathrm{M}_{\mathrm{n}}$ values of 29 and $21 \mathrm{~kg} / \mathrm{mol}$ and $\oslash$ values of 1.5 and 1.3 respectively. ${ }^{1} \mathrm{H}$ NMR spectroscopic data were consistent with the incorporation of the end-caps at the PEtG terminus (Figures S11, S12). TGA confirmed complete end-capping, but while PEtG-MMT had a $\mathrm{T}_{\mathrm{o}}$ of $168^{\circ} \mathrm{C}$, PEtG-DMT had a $\mathrm{T}_{\mathrm{o}}$ of only $131{ }^{\circ} \mathrm{C}$, which is much lower than all of the other end-capped PEtGs. TGA of $\mathbf{8}$ suggested that this can be attributed to the relatively poor thermal stability of the trityl moiety as 8 undergoes degradation with a $\mathrm{T}_{\mathrm{o}}$ of only $78{ }^{\circ} \mathrm{C}$ (Figure S45).

The acid triggered depolymerizations of PEtG-MMT and PEtG-DMT were studied in 9:1 $\mathrm{CD}_{3} \mathrm{CN}: \mathrm{D}_{2} \mathrm{O}$. Normally it is ideal to adjust the $\mathrm{pH}$ using buffers, but the high acetonitrile content of the solvent mixture makes buffer salts insoluble, so instead varying concentrations of acetic acid were added to the $\mathrm{CD}_{3} \mathrm{CN}: \mathrm{D}_{2} \mathrm{O}$ solutions. As shown in Figure 4a and S34, PEtG-MMT underwent end-cap cleavage and complete depolymerization over $\sim 48$ days in the presence of $510 \mathrm{mM}$ acetic acid, and with a slightly slower rate in $340 \mathrm{mM}$ acetic acid. In the absence of acetic acid $\sim 18 \%$ depolymerization was observed over this time period (Figure S35). Furthermore, the addition of $510 \mathrm{mM}$ acetic acid to PEtG-control did not lead to any significant depolymerization over 48 days (Figure S36). Although PEtG is a polyacetal, these acetals are not sensitive to mildly acidic conditions as the adjacent electron-withdrawing ester groups make 
them less susceptible to acidic cleavage in comparison with other polyacetals and

polyketals. ${ }^{61,62,65}$
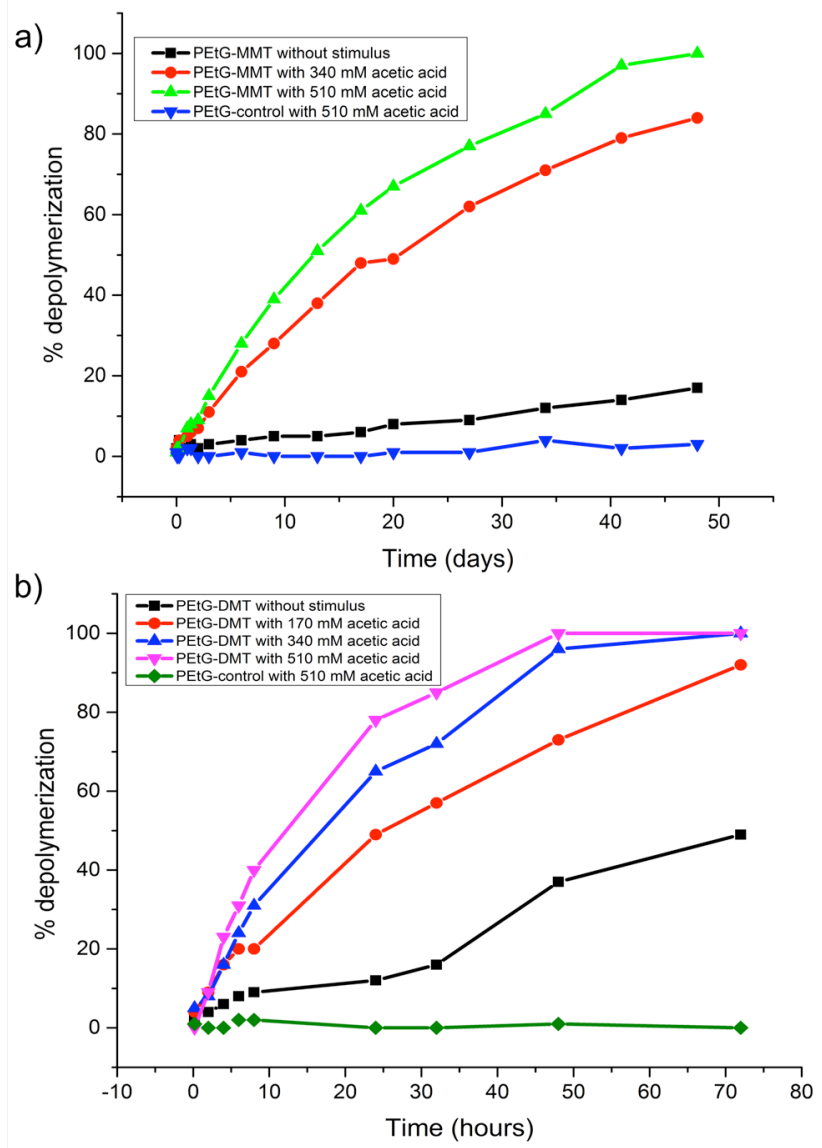

Figure 4. Percent depolymerization versus time for a) PEtG-MMT and b) PEtG-DMT in the absence and presence of varying concentrations of acetic acid.

The presence of two methoxy groups in the end-cap of PEtG-DMT was expected to lead to more rapid cleavage and subsequent depolymerization under acidic conditions ${ }^{66}$ and indeed this was the case. As shown in Figure $4 \mathrm{~b}$ and S37, complete end-cap cleavage and depolymerization occurred over only 2 days in the presence of $340 \mathrm{mM}$ or $510 \mathrm{mM}$ acetic acid and at a slightly slower rate in the presence of $170 \mathrm{mM}$ acetic acid. However, $\sim 50 \%$ depolymerization also occurred for PEtG-DMT without added acetic acid (Figure S38). This observation is 
characteristic of the typical trade-off with $\mathrm{pH}$-sensitive groups where faster cleavage at mildly acidic $\mathrm{pH}$ is commonly accompanied by faster cleavage under neutral conditions. Nevertheless, the results show that $\mathrm{pH}$-sensitive PEtGs can indeed be prepared and that the rate of triggering can be tuned by altering the chemical structure of the end-cap. Although the acetic acid concentrations employed in 9:1 $\mathrm{CD}_{3} \mathrm{CN}: \mathrm{D}_{2} \mathrm{O}$ during this study were quite high, the cleavage would be expected to be faster and to occur at mildly acidic $\mathrm{pH}$ in a fully aqueous system. ${ }^{66}$

\section{Development of multi-responsive end-caps}

While the above work demonstrates that diverse stimuli can be used to trigger PEtG depolymerization, for some applications it may be beneficial to develop a versatile end-capping strategy that allows the polymer to respond to multiple stimuli, either individually or simultaneously. To prepare an end-cap responsive to multiple stimuli, the previously reported aniline $9^{46}$ was reacted with chloroformate 4 in the presence of $\mathrm{Na}_{2} \mathrm{CO}_{3}$ in $\mathrm{THF} / \mathrm{H}_{2} \mathrm{O}$ at $0{ }^{\circ} \mathrm{C}$ to functionalize the aniline group selectively, affording compound $\mathbf{1 0}$ (Scheme 3). The benzylic alcohol of $\mathbf{1 0}$ was then reacted with phosgene to provide the chloroformate-activated end-cap $\mathbf{1 1 .}$ The $o$-nitrobenzyl moiety on this end-cap provides sensitivity to UV light,${ }^{67}$ but also to $\mathrm{Zn}$ /acetic $\operatorname{acid}^{68}$ (Scheme S1). At the same time, the phenylboronic acid pinacol ester is responsive to $\mathrm{H}_{2} \mathrm{O}_{2}$. After fragmentation via the mechanism shown in Figure 2a, the resulting aniline can undergo a 1,4-elimination to release the PEtG, triggering depolymerization (Scheme S1). In addition, using this simple synthetic route, it should be possible to replace chloroformate $\mathbf{4}$ with other chloroformates such as $\mathbf{5}$ and $\mathbf{6}$, such that this route can be used to prepare PEtG responsive to 
UV light, Zn/acetic acid and an additional stimulus, provided a chloroformate responsive to that stimulus can be prepared. Chloroformate $\mathbf{1 1}$ was used to cap PEtG as described above (Scheme 2), providing PEtG-multi, with an $\mathrm{M}_{\mathrm{n}}$ of $41 \mathrm{~kg} / \mathrm{mol}$ and $\doteq$ of 1.6 (Table 1). TGA confirmed that the polymer was well end-capped and its thermal properties were similar to those of other PEtGs.

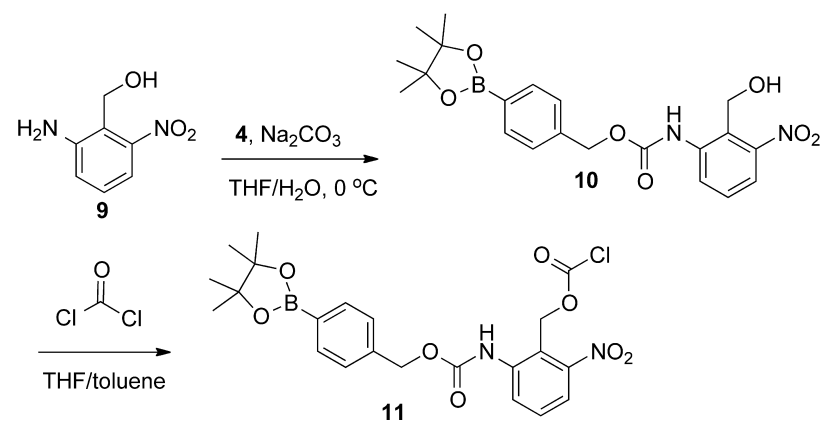

Scheme 3. Synthesis of multi-responsive end-cap 11.

The depolymerization behaviour of PEtG-multi was studied in the presence and absence of the relevant stimuli in 9:1 $\mathrm{CD}_{3} \mathrm{CN}: \mathrm{D}_{2} \mathrm{O}$. As shown in Figures 5 and $\mathrm{S} 39$, irradiation of PEtG-multi for 20 min with UV light followed by incubation in the solvent resulted in $\sim 50 \%$ depolymerization over 2 days. The addition of $100 \mathrm{mM} \mathrm{H}_{2} \mathrm{O}_{2}$ alone and the combination treatment of 20 min of UV light irradiation and $130 \mathrm{mM} \mathrm{H}_{2} \mathrm{O}_{2}$ led slightly faster rates of depolymerization (Figure S40-S41). While the result using UV light as a stimulus was similar to that previously observed for PEtG with a photoresponsive 6-nitroveratryl end-cap, ${ }^{24}$ the rate of depolymerization using $\mathrm{H}_{2} \mathrm{O}_{2}$ was significantly slower for PEtG-multi than for PEtG-boronate (Figure 3b). Following oxidative cleavage of the phenylboronic acid pinacol ester in PEtG-multi by $\mathrm{H}_{2} \mathrm{O}_{2}$, the molecule must undergo a 1,6-elimination, loss of $\mathrm{CO}_{2}, 1,4$-elimination, and finally a second loss of $\mathrm{CO}_{2}$ prior to the release of the hemiacetal-terminated $\mathrm{PEtG}$ for depolymerization 
(Scheme S1). On the other hand, PEtG-boronate only requires a single sequence of

1,6-elimination and loss of $\mathrm{CO}_{2}$. While such elimination reactions can be very rapid under fully aqueous conditions, as the solvent polarity is decreased (such as through addition of $\mathrm{CD}_{3} \mathrm{CN}$ ), these reactions are known to be significantly slowed and this may be responsible for the slower rate of complete end-cap cleavage and thus the overall depolymerization rate of PEtG-multi. ${ }^{57,69}$ Another possible explanation is that the reactive quinone methides or azoquinone methides generated upon end-cap fragmentation can be trapped by the hydroxyl terminus of depolymerizing PEtG (Scheme S2). This would generate benzyl ether capped polymers that can still undergo elimination to continue depolymerization, but at a slower rate. This would explain the initial rapid phase of depolymerization, followed by the slower phase of depolymerization.

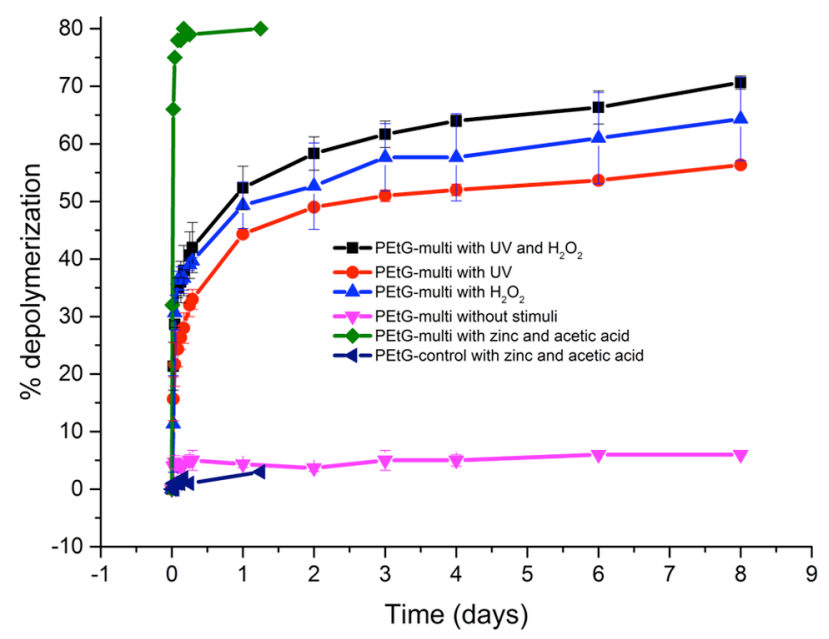

Figure 5. Depolymerization versus time for PEtG-multi following exposure to UV light, $\mathrm{H}_{2} \mathrm{O}_{2}$, $\mathrm{Zn}$ /acetic acid, and combinations of these stimuli.

The addition of $\mathrm{Zn}(250 \mathrm{mM})$ and acetic acid $(700 \mathrm{mM})$, conditions previously reported for triggering dendrimer degradation, ${ }^{68}$ afforded $\sim 80 \%$ depolymerization within $6 \mathrm{~h}$ (Figure S42). 
PEtG-control underwent less than 5\% depolymerization when exposed to Zn (250 mM) and acetic acid (700 mM) for $30 \mathrm{~h}$ (Figure S43). Control experiments described above and previously reported $^{24}$ have already confirmed the stability of PEtG-control in the presence of UV light and $\mathrm{H}_{2} \mathrm{O}_{2}$. Furthermore, a control experiment where PEtG-multi was not exposed to any stimuli showed that less than 5\% depolymerization occurred over 8 days (Figure S44). Overall, these results demonstrate that PEtG can be designed to respond to multiple different stimuli through careful engineering of the end-cap, but that the requirement for multiple sequential reactions can slow the initiation of depolymerization.

\section{Development of a cross-linkable end-cap}

Polyglyoxylates are of significant interest as coating materials as they undergo degradation through a surface erosion mechanism with the depolymerization time tunable based on the coating thickness. ${ }^{35}$ In order to cure the coating and tune its physical properties, it was desirable to develop a curing process for the polymer. Thus, an end-cap that would allow for cross-linking was designed. Thiol-ene reactions have been extensively used to prepare cross-linked polymer networks in recent years, ${ }^{70,71}$ so it was envisioned that an end-cap bearing a stimuli-responsive moiety as well as multiple alkenes would be ideal for subsequent cross-linking using a multivalent thiol.

Synthesis of the end-cap began from the previously reported benzoic acid derivative $\mathbf{1 2}^{\mathbf{4 7}}$ and amine $13,{ }^{48}$ which were coupled using $N$-(3-dimethylaminopropyl)- $N$ '-ethylcarbodiimide hydrochloride (EDC $\cdot \mathrm{HCl})$ in the presence of 4-(dimethylamino)pyridine (DMAP) to afford the amide 14 (Scheme 4). This amide was then activated using phosgene in THF/toluene to provide 
the chloroformate 15. PEtG was synthesized and end-capped using $\mathbf{1 5}$ as described above to afford PEtG-trialkene (Scheme 2) with the slight modification that due to the sterically bulky nature of this end-cap it was necessary to keep the end-capping conditions at $-20{ }^{\circ} \mathrm{C}$ for 6 hours instead of immediately allowing the solution to gradually warm to room temperature. This ensured that the polymer had sufficient time to be end-capped at $-20{ }^{\circ} \mathrm{C}$, as it would otherwise depolymerize when warmed to room temperature. The $\mathbf{M}_{\mathrm{n}}$ of PEtG-trialkene was $11 \mathrm{~kg} / \mathrm{mol}(\bigoplus$ $=1.7)$, which is lower than that of the other polymers due to the end-capping challenges.

However, thermal analyses showed that it was well end-capped and had a $\mathrm{T}_{\mathrm{g}}$ similar to that of the other PEtGs.

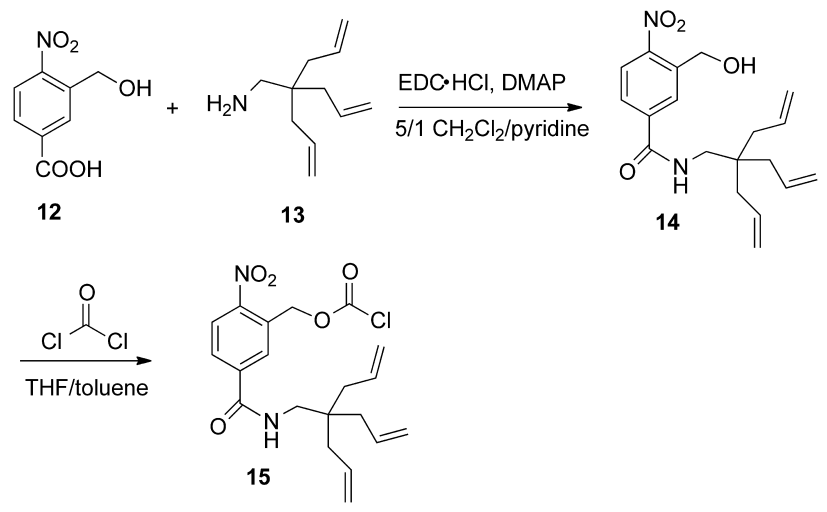

Scheme 4. Synthesis of cross-linkable end-cap 15.

The cross-linking of PEtG-trialkene was performed using pentaerythritol tetrakis(3-mercaptopropionate) (16) in toluene at $60^{\circ} \mathrm{C}$ using 2,2'azobis(2-methylpropionitrile) (AIBN) as an initiator to provide PEtG-cross-linked (Scheme 5). After the reaction, unreacted polymer and small molecules were removed by extracting the gel 3 times with $\mathrm{CH}_{2} \mathrm{Cl}_{2}$. The resulting gel content was $72 \%$. Infrared spectroscopy was used to confirm the reaction, as the peak at $1660 \mathrm{~cm}^{-1}$ corresponding to the $\mathrm{C}=\mathrm{C}$ stretch of the alkene almost entirely disappeared 
after cross-linking (Figure $\mathrm{S} 53$ ). In addition, the cross-linking resulted in an increase in the $\mathrm{T}_{\mathrm{g}}$ from $-7{ }^{\circ} \mathrm{C}$ for PEtG-trialkene to $5{ }^{\circ} \mathrm{C}$ for PEtG-cross-linked. The end-cap of PEtG-trialkene contains an $o$-nitrobenzyl moiety enabling it to respond to UV light irradiation, so the depolymerization of the network in response to UV light was explored. The PEtG-cross-linked network was immersed in 9:1 $\mathrm{CD}_{3} \mathrm{CN}: \mathrm{D}_{2} \mathrm{O}$, then irradiated with UV light $\left(2.8 \mathrm{~mW} / \mathrm{cm}^{2}\right)$. Prior to irradiation, only peaks corresponding to $\mathrm{CD}_{2} \mathrm{HCN}$ and $\mathrm{DOH}$ were observed in the ${ }^{1} \mathrm{H}$ NMR spectrum, as the gel-like network was completely insoluble. After $5 \mathrm{~h}$ of UV irradiation, peaks corresponding to the expected depolymerization product EtGH were clearly observed, confirming that depolymerization of the network could be triggered (Figure S45). Only a small amount of particulate material remained, likely corresponding to the product of the reaction between the end-cap and cross-linker 16. Thus, PEtG can be both incorporated into polymer networks to tune its properties and can also be depolymerized within network structures. It is anticipated that the structure and properties of the cross-linked networks can be optimized for different applications by varying the structure and ratio of the thiol cross-linking agent.

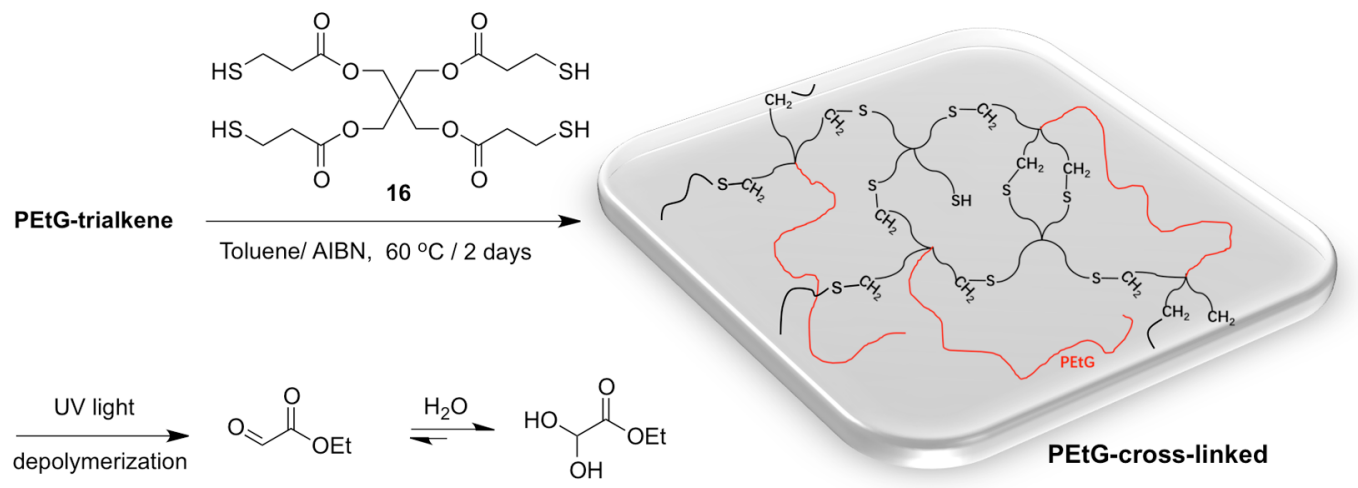

Scheme 5. Cross-linking of PEtG-trialkene and UV light triggered depolymerization of the resulting PEtG-cross-linked. 


\section{Mechanically triggered degradation of PEtG}

It was recently demonstrated that high molar mass poly(o-phthalaldehyde) could be cleaved by the mechanical force induced by ultrasound. ${ }^{27}$ Unlike conventional polymers such as PMMA, that simply undergo chain scission to produce lower molar mass polymers, chain cleavage of poly $(o$-phthalaldehyde) induced end-to-end depolymerization resulting in the conversion of polymers to monomers. Although not technically an end-capping strategy, we sought to determine whether this mechanism of chain scission would also apply to high molar mass PEtG.

In order to evaluate this, the response of high molar mass PEtG-disulfide-a $\left(\mathrm{M}_{\mathrm{n}}=250\right.$ $\mathrm{kg} / \mathrm{mol})$ and lower molar mass PEtG-disulfide-b $\left(\mathrm{M}_{\mathrm{n}}=26 \mathrm{~kg} / \mathrm{mol}\right)$ to ultrasound was studied and compared. Dilute $(1 \mathrm{mg} / \mathrm{mL})$ solutions of the polymers in THF were prepared in order to avoid polymer chain entanglement and then pulsed ultrasound was applied at $-20^{\circ} \mathrm{C}(1 \mathrm{~s}$ on, $0.5 \mathrm{~s}$ off $)$. The solutions were removed at various time points and analyzed by SEC. After $5 \mathrm{~min}$, the $\mathrm{M}_{\mathrm{n}}$ of PEtG-disulfide-a had decreased from $250 \mathrm{~kg} / \mathrm{mol}$ to $113 \mathrm{~kg} / \mathrm{mol}$ (Figure 6a and c). With additional sonication over $60 \mathrm{~min}$ the molar mass continued to decrease to $46 \mathrm{~kg} / \mathrm{mol}$ and the intensity of the refractive index (RI) signal in SEC decreased to almost baseline values suggesting that the polymer had almost completely depolymerized. Over this time period, the reduction in $\mathrm{M}_{\mathrm{n}}$ and $\mathrm{RI}$ signal intensity arose from the continual cleavage of high molar mass polymers by ultrasound, combined with the depolymerization of these cleaved chains to small molecules. On the other hand, neither the molar mass or RI signal intensity in SEC changed for PEtG-disulfide-b over 60 min of pulsed ultrasound (Figure $6 \mathrm{~b}$ and c). This is consistent with the previously reported molar mass threshold of $30 \mathrm{~kg} / \mathrm{mol}$ for polystyrene chain cleavage by 
ultrasonication. $^{72}$
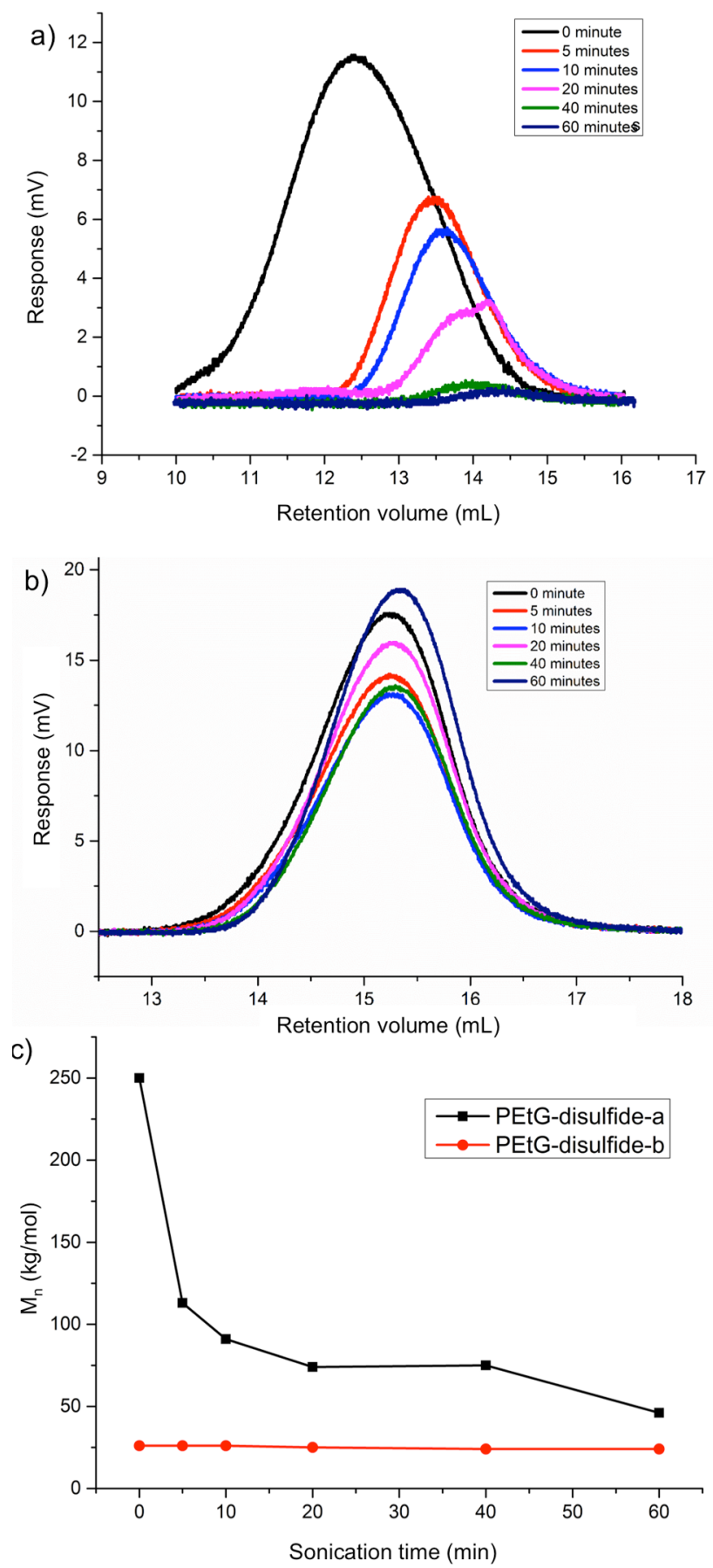

Figure 6. a-b) SEC traces (RI detection) for a) PEtG-disulfide-a and b) PEtG-disulfide-b

following different sonication times; c) Changes in $\mathrm{M}_{\mathrm{n}}$ for PEtG-disulfide-a and

PEtG-disulfide-b following different sonication times. 
Unlike most mechanically-induced chain scissions, that involve the generation of macroradicals, ${ }^{73}$ poly(o-phthalaldehyde) was demonstrated by trapping experiments to undergo heterolytic bond cleavage prior to depolymerization. ${ }^{27}$ Because PEtG also has a polyacetal backbone, it was proposed to follow a similar mechanism. To confirm this, ultrasound was applied to PEtG-disulfide-a as described above, but in the presence of tert-butyldimethylsilyl chloride, an electrophilic trapping agent capable of reacting with the nucleophilic terminus of heterolytically cleaved PEtG. Depolymerization was significantly slowed in comparison to without the trapping agent, suggesting that a heterolytic cleavage mechanism also applies to

\section{PEtG (Figures S54-S55).}

These results confirm that mechanical triggering with ultrasound is an additional stimulus that can be applied to initiate the depolymerization of PEtG. This should apply to PEtG with any end-cap, provided the molar mass is sufficiently high. Ultrasound is of particular interest for biomedical applications as ultrasonic radiation is routinely applied for medical imaging and there has been substantial interest in the development of drug delivery systems that are responsive to ultrasound. $^{74,75}$

\section{Conclusions}

It was demonstrated that a phenylboronic acid pinacol ester, disulfide, and azobenzene could be converted into chloroformates and used to end-cap PEtG. This allowed PEtG to undergo depolymerization in response to $\mathrm{H}_{2} \mathrm{O}_{2}$ and DTT, while the non-responsive PEtG-control was stable under these conditions. Relatively high concentrations of $\mathrm{H}_{2} \mathrm{O}_{2}$ and DTT were required due to the trapping of these stimuli by the depolymerization product. It is possible that this drawback 
will be mitigated in fully aqueous conditions, where water will be present at 10 -fold higher concentration that in $9: 1 \mathrm{CD}_{3} \mathrm{CN}: \mathrm{D}_{2} \mathrm{O}$, but testing this will require the synthesis of water-soluble polyglyoxylates or water-dispersible block copolymers. It was also shown that acid-sensitive end-caps could be introduced to PEtG using trityl chlorides and that their sensitivity could be tuned by adjusting the number of electron donating methoxy substituents on the phenyl ring. Next, a new end-cap that was responsive to multiple stimuli including UV light, $\mathrm{H}_{2} \mathrm{O}_{2}$, and $\mathrm{Zn}$ /acetic acid was developed. It is envisioned that the backbone and synthetic method for this molecule can be applied to introduce other stimuli-responsive groups, providing a versatile strategy towards multi-responsive end-caps. Furthermore, it was demonstrated that a cross-linkable trialkene could be incorporated into a photo-responsive end-cap, allowing cross-linked networks of PEtG to be formed. Finally, the backbone of high molar mass PEtG could also be cleaved mechanically, thereby initiating depolymerization. Overall, these new end-caps significantly expand the utility of PEtG, by expanding the available stimuli from UV light to many other conditions, some of which are relevant to the physiological environments associated with disease states such as cancer and inflammation. It is also anticipated that these end-caps and triggering mechanisms will be useful for the growing field of stimuli-responsive backbone cleavable and end-to-end depolymerizable materials. Current work is focused on the incorporation of these triggering mechanisms into PEtG block copolymers and the study of their assemblies in aqueous solution.

\section{Supporting information}


Additional experimental procedures, NMR spectra, thermal data, depolymerization data, IR data for cross-linking, proposed cleavage mechanisms for the multi-responsive end-cap. This material is available free of charge via the Internet at http://pubs.acs.org.

\section{Acknowledgements}

The authors thank the Natural Sciences and Engineering Research Council of Canada (Discovery Grant and Strategic Project Grant) for funding this work as well as Andrew Wong and Alex Prinzen for providing the azobenzene starting material.

\section{References}

(1) Tschan, M. J.-L.; Brulé, E.; Haquette, P.; Thomas, C. M. Synthesis of Biodegradable Polymers from Renewable Resources. Polym. Chem. 2012, 3, 836-851.

(2) Hwang, S. W.; Song, J. K.; Huang, X.; Cheng, H.; Kang, S. K.; Kim, B. H.; Kim, J. H.; Yu, S.; Huang, Y.; Rogers, J. A. High - Performance Biodegradable/Transient Electronics on Biodegradable Polymers. Adv. Mater. 2014, 26, 3905-3911.

(3) Nicolas, J.; Mura, S.; Brambilla, D.; Mackiewicz, N.; Couvreur, P. Design, Functionalization Strategies and Biomedical Applications of Targeted Biodegradable/Biocompatible Polymer-Based Nanocarriers for Drug Delivery. Chem. Soc. Rev. $\mathbf{2 0 1 3}, 42,1147-1235$.

(4) Woodruff, M. A.; Hutmacher, D. W. The Return of a Forgotten Polymer-Polycaprolactone in the 21st Century. Prog. Polym. Sci. 2010, 35, 1217-1256. 
(5) Anderson, J. M.; Shive, M. S. Biodegradation and Biocompatibility of PLA and PLGA Microspheres. Adv. Drug Delivery Rev. 2012, 64, 72-82.

(6) Pitt, G.; Gratzl, M.; Kimmel, G.; Surles, J.; Sohindler, A. Aliphatic Polyesters II. The Degradation of Poly(DL-lactide), Poly( $\varepsilon$-caprolactone), and Their Copolymers in Vivo. Biomaterials 1981, 2, 215-220.

(7) Li, S. Hydrolytic Degradation Characteristics of Aliphatic Polyesters Derived from Lactic and Glycolic Acids. J. Biomed. Mater. Res. 1999, 48, 342-353.

(8) Hakkarainen, M.; Höglund, A.; Odelius, K.; Albertsson, A.-C. Tuning the Release Rate of Acidic Degradation Products through Macromolecular Design of Caprolactone-Based Copolymers. J. Am. Chem. Soc. 2007, 129, 6308-6312.

(9) Källrot, M.; Edlund, U.; Albertsson, A.-C. Covalent Grafting of Poly(L-lactide) to Tune the in Vitro Degradation Rate. Biomacromolecules 2007, 8, 2492-2496.

(10) Roth, M. E.; Green, O.; Gnaim, S.; Shabat, D. Dendritic, Oligomeric, and Polymeric Self-Immolative Molecular Amplification. Chem. Rev. 2015, 116, 1309-1352.

(11) Fan, B.; Gillies, E. R. Self-Immolative Polymers. Encycl. Polym. Sci. Technol. 2015, 1-35.

(12) Phillips, S. T.; DiLauro, A. M. Continuous Head-to-Tail Depolymerization: An Emerging Concept for Imparting Amplified Responses to Stimuli-Responsive Materials. ACS Macro Lett. 2014, 3, 298-304.

(13) Alouane, A.; Labruere, R.; Le Saux, T.; Schmidt, F.; Jullien, L. Self - Immolative Spacers: Kinetic Aspects, Structure - Property Relationships, and Applications. Angew. Chem. Int. Ed. 2015, 54, 7492-7509. 
(14) Sagi, A.; Weinstain, R.; Karton, N.; Shabat, D. Self-Immolative Polymers. J. Am. Chem.

Soc. 2008, 130, 5434-5435.

(15) DeWit, M. A.; Gillies, E. R. A Cascade Biodegradable Polymer Based on Alternating Cyclization and Elimination Reactions. J. Am. Chem. Soc. 2009, 131, 18327-18334.

(16) Liu, G.; Zhang, G.; Hu, J.; Wang, X.; Zhu, M.; Liu, S. Hyperbranched Self-Immolative Polymers (HSIPs) for Programmed Payload Delivery and Ultrasensitive Detection. J. Am. Chem. Soc. 2015, 137, 11645-11655.

(17) McBride, R. A.; Gillies, E. R. Kinetics of Self-Immolative Degradation in a Linear Polymeric System: Demonstrating the Effect of Chain Length. Macromolecules 2013, 46, 5157-5166.

(18) Chen, E. K.; McBride, R. A.; Gillies, E. R. Self-Immolative Polymers Containing Rapidly Cyclizing Spacers: Toward Rapid Depolymerization Rates. Macromolecules 2012, 45, 7364-7374.

(19) DeWit, M. A.; Beaton, A.; Gillies, E. R. A Reduction Sensitive Cascade Biodegradable Linear Polymer. J. Polym. Sci., Part A: Polym. Chem. 2010, 48, 3977-3985.

(20) Olah, M. G.; Robbins, J. S.; Baker, M. S.; Phillips, S. T. End-Capped Poly(benzyl ethers): Acid and Base Stable Polymers That Depolymerize Rapidly from Head-to-Tail in Response to Specific Applied Signals. Macromolecules 2013, 46, 5924-5928.

(21) Seo, W.; Phillips, S. T. Patterned Plastics That Change Physical Structure in Response to Applied Chemical Signals. J. Am. Chem. Soc. 2010, 132, 9234-9235.

(22) DiLauro, A. M.; Robbins, J. S.; Phillips, S. T. Reproducible and Scalable Synthesis of 
End-Cap-Functionalized Depolymerizable Poly(phthalaldehydes). Macromolecules 2013, 46, 2963-2968.

(23) DiLauro, A. M.; Lewis, G. G.; Phillips, S. T. Self-Immolative

Poly(4,5-dichlorophthalaldehyde) and Its Applications in Multi-Stimuli-Responsive Macroscopic Plastics. Angew. Chem. Int. Ed. 2015, 127, 6298-6303.

(24) Fan, B.; Trant, J. F.; Wong, A. D.; Gillies, E. R. Polyglyoxylates: A Versatile Class of Triggerable Self-Immolative Polymers from Readily Accessible Monomers. J. Am. Chem. Soc. 2014, 136, 10116-10123.

(25) Kaitz, J. A.; Moore, J. S. Functional Phthalaldehyde Polymers by Copolymerization with Substituted Benzaldehydes. Macromolecules 2013, 46, 608-612.

(26) Kaitz, J. A.; Moore, J. S. Copolymerization of $o$-Phthalaldehyde and Ethyl Glyoxylate: Cyclic Macromolecules with Alternating Sequence and Tunable Thermal Properties. Macromolecules 2014, 47, 5509-5513.

(27) Diesendruck, C. E.; Peterson, G. I.; Kulik, H. J.; Kaitz, J. A.; Mar, B. D.; May, P. A.; White, S. R.; Martínez, T. J.; Boydston, A. J.; Moore, J. S. Mechanically Triggered Heterolytic Unzipping of a Low-Ceiling-Temperature Polymer. Nat. Chem. 2014, 6

(28) de Gracia Lux, C.; McFearin, C. L.; Joshi-Barr, S.; Sankaranarayanan, J.; Fomina, N.; Almutairi, A. Single UV or near IR Triggering Event Leads to Polymer Degradation into Small Molecules. ACS Macro Lett. 2012, 1, 922-926.

(29) Li, Y.; Liu, G.; Wang, X.; Hu, J.; Liu, S. Enzyme - Responsive Polymeric Vesicles for Bacterial - Strain - Selective Delivery of Antimicrobial Agents. Angew. Chem. Int. Ed. 2016, 128, 
1792-1796.

(30) Liu, G.; Wang, X.; Hu, J.; Zhang, G.; Liu, S. Self-Immolative Polymersomes for

High-Efficiency Triggered Release and Programmed Enzymatic Reactions. J. Am. Chem. Soc.

2014, 136, 7492-7497.

(31) Lewis, G. G.; Robbins, J. S.; Phillips, S. T. Point-of-Care Assay Platform for Quantifying

Active Enzymes to Femtomolar Levels Using Measurements of Time as the Readout. Anal. Chem.

2013, $85,10432-10439$.

(32) Lewis, G. G.; Robbins, J. S.; Phillips, S. T. Phase-Switching Depolymerizable

Poly(carbamate) Oligomers for Signal Amplification in Quantitative Time-Based Assays.

Macromolecules 2013, 46, 5177-5183.

(33) Zhang, H.; Yeung, K.; Robbins, J. S.; Pavlick, R. A.; Wu, M.; Liu, R.; Sen, A.; Phillips, S.

T. Self-Powered Microscale Pumps Based on Analyte-Initiated Depolymerization Reactions.

Angew. Chem. Int. Ed. 2012, 51, 2400-2404.

(34) Kim, H.; Mohapatra, H.; Phillips, S. T. Rapid, On - Command Debonding of Stimuli -

Responsive Cross - Linked Adhesives by Continuous, Sequential Quinone Methide Elimination

Reactions. Angew. Chem. Int. Ed. 2015, 54, 13063-13067.

(35) Fan, B.; Trant, J. F.; Yardley, R. E.; Pickering, A. J.; Lagugné-Labarthet, F.; Gillies, E. R. Photocontrolled Degradation of Stimuli-Responsive Poly(ethyl glyoxylate): Differentiating Features and Traceless Ambient Depolymerization. Macromolecules 2016, 49, 7196-7203.

(36) Esser-Kahn, A. P.; Sottos, N. R.; White, S. R.; Moore, J. S. Programmable Microcapsules from Self-Immolative Polymers. J. Am. Chem. Soc. 2010, 132, 10266-10268. 
(37) DiLauro, A. M.; Abbaspourrad, A.; Weitz, D. A.; Phillips, S. T. Stimuli-Responsive CoreShell Microcapsules with Tunable Rates of Release by Using a Depolymerizable Poly(phthalaldehyde) Membrane. Macromolecules 2013, 46, 3309-3313.

(38) Baker, M. S.; Kim, H.; Olah, M. G.; Lewis, G. G.; Phillips, S. T. Depolymerizable Poly(benzyl ether)-Based Materials for Selective Room Temperature Recycling. Green Chem. 2015, 17, 4541-4545.

(39) Brasch, M.; Voets, I. K.; Koay, M. S.; Cornelissen, J. J. Phototriggered Cargo Release from Virus-Like Assemblies. Faraday Discuss. 2013, 166, 47-57.

(40) Yeung, K.; Kim, H.; Mohapatra, H.; Phillips, S. T. Surface-Accessible Detection Units in Self-Immolative Polymers Enable Translation of Selective Molecular Detection Events into Amplified Responses in Macroscopic, Solid-State Plastics. J. Am. Chem. Soc. 2015, 137, $5324-5327$.

(41) Belloncle, B.; Bunel, C.; Menu-Bouaouiche, L.; Lesouhaitier, O.; Burel, F. Study of the Degradation of Poly(ethyl glyoxylate): Biodegradation, Toxicity and Ecotoxicity Assays. $J$. Polym. Environ. 2012, 20, 726-731.

(42) Brachais, C.; Huguet, J.; Bunel, C. Synthesis, Characterization and Stabilization of Poly(methyl glyoxylate). Polymer 1997, 38, 4959-4964.

(43) Brachais, C.; Huguet, J.; Bunel, C.; Brachais, L. In Vitro Degradation of Poly(methyl glyoxylate) in Water. Polymer 1998, 39, 883-890.

(44) Henne, W. A.; Kularatne, S. A.; Ayala-López, W.; Doorneweerd, D. D.; Stinnette, T. W.; Lu, Y.; Low, P. S. Synthesis and Activity of Folate Conjugated Didemnin B for Potential Treatment of 
Inflammatory Diseases. Bioorg. Med. Chem. Lett. 2012, 22, 709-712.

(45) Wong, A. D.; Prinzen, A. L.; Gillies, E. R. Poly(ester amide)s with Pendant Azobenzenes: Multi-Responsive Self-Immolative Moieties for Modulating Polymer Assemblies. Polym. Chem. 2016, 7, 1871-1881.

(46) Ida, Y.; Matsubara, A.; Nemoto, T.; Saito, M.; Hirayama, S.; Fujii, H.; Nagase, H.

Synthesis of Quinolinomorphinan Derivatives as Highly Selective $\Delta$ Opioid Receptor Ligands. Biooorg. Med. Chem. 2012, 20, 5810-5831.

(47) Aujard, I.; Benbrahim, C.; Gouget, M.; Ruel, O.; Baudin, J. B.; Neveu, P.; Jullien, L. $O$-Nitrobenzyl Photolabile Protecting Groups with Red-Shifted Absorption: Syntheses and Uncaging Cross-Sections for One-and Two-Photon Excitation. Chem. Eur. J. 2006, 12, 6865-6879.

(48) Wood, M. C.; Leitch, D. C.; Yeung, C. S.; Kozak, J. A.; Schafer, L. L. Chiral Neutral Zirconium Amidate Complexes for the Asymmetric Hydroamination of Alkenes. Angew. Chem. Int. Ed. 2007, 46, 354-358.

(49) Huo, M.; Yuan, J.; Tao, L.; Wei, Y. Redox-Responsive Polymers for Drug Delivery: From Molecular Design to Applications. Polym. Chem. 2014, 5, 1519-1528.

(50) Lallana, E.; Tirelli, N. Oxidation - Responsive Polymers: Which Groups to Use, How to Make Them, What to Expect from Them (Biomedical Applications). Macromol. Chem. Phys 2013, 214, 143-158.

(51) Mura, S.; Nicolas, J.; Couvreur, P. Stimuli-Responsive Nanocarriers for Drug Delivery. Nat. Mater. 2013, 12, 991-1003. 
(52) Saito, G.; Swanson, J. A.; Lee, K. D. Drug Delivery Strategy Utilizing Conjugation Via

Reversible Disulfide Linkages: Role and Site of Cellular Reducing Activities. Adv. Drug Delivery Rev. 2003, 55, 199-215.

(53) Kuppusamy, P.; Li, H.; Ilangovan, G.; Cardounel, A. J.; Zweier, J. L.; Yamada, K.; Krishna, M. C.; Mitchell, J. B. Noninvasive Imaging of Tumor Redox Status and Its Modification by Tussue Glutathione Levels. Cancer Res. 2002, 62, 307-312.

(54) Gough, D. R.; Cotter, T. G. Hydrogen Peroxide: A Jekyll and Hyde Signalling Molecule. Cell Death \& Disease 2011, 2, e213.

(55) Lo, L.-C.; Chu, C.-Y. Development of Highly Selective and Sensitive Probes for Hydrogen Peroxide. Chem. Commun. 2003, 2728-2729.

(56) Jain, A. K.; Machhindra, G. G.; Desai, D. C.; Borhade, N.; Senthilkumar, S. P.; Dhiman, M.; Mangu, N. K.; Mali, S. V.; Dubash, N. P.; Halder, S.; Satyam, A. Mutual Prodrugs Containing Bio-Cleavable and Drug Releasable Disulfide Linkers. Bioorg. Chem. 2013, 49, 40-48.

(57) Wong, A. D.; Güngör, T. M.; Gillies, E. R. Multiresponsive Azobenzene End-Cap for Self-Immolative Polymers. ACS Macro Lett. 2014, 3, 1191-1195.

(58) Fina, N. J.; Edwards, J. O. The Alpha Effect. A Review. Int. J. Chem. Kinet. 1973, 5, 1-26.

(59) Olejniczak, J.; Huu, V. A. N.; Lux, J.; Grossman, M.; He, S.; Almutairi, A. Light-Triggered Chemical Amplification to Accelerate Degradation and Release from Polymeric Particles. Chem. Commun. 2015, 51, 16980-16983.

(60) Liu, J.; Huang, Y.; Kumar, A.; Tan, A.; Jin, S.; Mozhi, A.; Liang, X. J. pH-Sensitive Nano-Systems for Drug Delivery in Cancer Therapy. Biotechnol. Adv. 2014, 32, 693-710. 
(61) Hefferman, M. J.; Murthy, N. Polyketal Nanoparticles: A New pH-Sensitive Biodegradable Drug Delivery Vehicle. Bioconjugate Chem. 2005, 16, 1340-1342.

(62) Jain, R.; Standley, S. M.; Frechet, J. M. J. Synthesis and Degradation of pH-Sensitive Linear Poly(amidoamine)s. Macromolecules 2007, 40, 452-457.

(63) Gillies, E. R.; Jonsson, T. B.; Fréchet, J. M. J. Stimuli-Responsive Supramolecular Assemblies of Linear-Dendritic Copolymers. J. Am. Chem. Soc. 2004, 126, 11936-11943.

(64) Shchepinov, M. S.; Korshun, V. A. Recent Applications of Bifunctional Trityl Groups. Chem. Soc. Rev. 2003, 32, 170-180.

(65) Rickerby, J.; Prabhakar, R.; Ali, M.; Knowles, J.; Brocchini, S. Water-Soluble Polyacetals Derived from Diphenols. J. Mater. Chem. 2005, 15, 1849-1856.

(66) Wuts, P. G. M.; Greene, T. W. Protective Groups in Organic Synthesis. 4th Ed.; Wiley and Sons Inc: Hoboken, New Jersey, 2007.

(67) Bochet, C. G. Photolabile Protecting Groups and Linkers. J. Chem. Soc., Perkin Trans. 1 2002, 125-142.

(68) Warnecke, A.; Kratz, F. 2, 4-Bis(hydroxymethyl) Aniline as a Building Block for Oligomers with Self-Eliminating and Multiple Release Properties. J. Org. Chem. 2008, 73, 1546-1552.

(69) Robbins, J. S.; Schmid, K. M.; Phillips, S. T. Effects of Electronics, Aromaticity, and Solvent Polarity on the Rate of Azaquinone-Methide-Mediated Depolymerization of Aromatic Carbamate Oligomers. J. Org. Chem. 2013, 78, 3159-3169.

(70) Kade, M. J.; Burke, D. J.; Hawker, C. J. The Power of Thiol-Ene Chemistry. J. Polym. Sci., 
Part A: Polym. Chem. 2010, 48, 743-750.

(71) Hoyle, C. E.; Bowman, C. N. Thiol-Ene Click Chemistry. Angew. Chem. Int. Ed. 2010, 49, $1540-1573$.

(72) Nguyen, T. Q.; Liang, Q. Z.; Kausch, H.-H. Kinetics of Ultrasonic and Transient Elongational Flow Degradation: A Comparative Study. Polymer 1997, 38, 3783-3793.

(73) Caruso, M. M.; Davis, D. A.; Shen, Q.; Odom, S. A.; Sottos, N. R.; White, S. R.; Moore, J. S. Mechanically-Induced Chemical Changes in Polymeric Systems. Chem. Rev. 2009, 109, $5755-5798$.

(74) Sirsi, S. R.; Borden, M. A. State-of-the-Art Materials for Ultrasound-Triggered Drug Delivery. Adv. Drug Delivery Rev. 2014, 72, 3-14.

(75) Liu, H. L.; Fan, C. H.; Ting, C. Y.; Yeh, C. K. Combining Microbubbles and Ultrasound for Drug Delivery to Brain Tumors: Current Progress and Overview. Theranostics 2014, 4, 432-444. 